\title{
Dietary total antioxidant capacity and the occurrence of metabolic syndrome and its components after a 3-year follow-up in adults: Tehran Lipid and Glucose Study
}

\author{
Zahra Bahadoran ${ }^{1}$, Mahdieh Golzarand ${ }^{1}$, Parvin Mirmiran², Niloofar Shiva ${ }^{1}$ and Fereidoun Azizi ${ }^{3}$
}

\begin{abstract}
Background: There is growing evidence that dietary antioxidants could have favorable effects on the attenuation and prevention of metabolic disorders. In the current study we investigated the association of dietary total antioxidant capacity (TAC) and metabolic syndrome (MetS) components and the occurrence of the MetS during a 3-year follow-up.

Methods: This longitudinal study was conducted in the framework of Tehran Lipid and Glucose Study, between 2006-2008 and 2009-2011, on 1983 adults, aged 19-70 y. The usual intakes of participant were measured using a validated semi-quantitative food frequency questionnaire and dietary TAC was estimated at baseline. The MetS components were assessed at baseline and 3 years later. Multiple logistic regression models were used to estimate the occurrence of the MetS and its components according to dietary TAC quartile categories.

Results: The mean age of participants was $40.4 \pm 13.0 \mathrm{y}$, and mean BMI was $27.03 \pm 4.9 \mathrm{~kg} / \mathrm{m}^{2}$ at baseline. After adjustment for potential confounding variables, TAC was associated with MetS components at baseline. Participant with highest TAC score had lower weight and abdominal fat gain during the 3 year follow-up. The chance of having the MetS, abdominal obesity and hypertension after 3 years decreased across the increasing dietary TAC quartile ( $P$ for trend $<0.01$ ). Dietary TAC more than $1080 \mu$ molTE/100 g of food, resulted in a 38\% decrease in the risk of central obesity $(\mathrm{OR}=0.62,95 \% \mathrm{Cl}=0.38-0.99)$.

Conclusion: We demonstrated that higher dietary antioxidant intakes have favorable effects on metabolic disorders and, more interestingly, prevent subsequent weight and abdominal fat gain during a 3-year follow-up.
\end{abstract}

Keywords: Dietary total antioxidant capacity, Antioxidant-rich foods, Metabolic syndrome

\section{Background}

Metabolic syndrome is a common multi-factorial disorder including abdominal obesity, insulin resistance, hypertension and dyslipidemia, leading to accelerated atherosclerosis and increased risk for diabetes [1,2]. There is growing evidences that this systemic disorder may be a result of oxidative stress [3,4]. It has been indicated that an impaired balance between free radical

\footnotetext{
* Correspondence: mirmiran@endocrine.ac.ir

${ }^{2}$ Department of Clinical Nutrition and Dietetics, Faculty of Nutrition Sciences and Food Technology, National Nutrition and Food Technology Research Institute, Shahid Beheshti University of Medical Sciences, No 46 Arghavan-egharbi St., Farahzadi Blv., Shahrak-e-Ghods, 19395-4741 Tehran, Iran Full list of author information is available at the end of the article
}

production and an impaired antioxidant defense system resulting in accumulation of oxidative damage, could playing important roles in pathological conditions such as insulin resistance, altered energy production and endothelial dysfunction as main risk factors of metabolic syndrome [5]. Dietary antioxidants have been reported to protect against oxidative damage and its complications [6] but the effects of antioxidants on the risk of MetS and related metabolic disorders have not been clarified and the results of clinical trials in this regard are inconsistent [7-9]. Since the evaluation of single antioxidant component may not reflect the total antioxidant power of diets and other possible interaction or 
synergetic effects of antioxidants, the concept of dietary total antioxidant capacity (TAC) was recently developed as a novel and relevant tool for assessment of the beneficial effects of dietary antioxidants $[10,11]$. The TAC of foods describes the ability of food antioxidants to scavenge free radicals and it is measured using the oxygen radical absorbance capacity (ORAC) assay [12]. Dietary TAC has been positively associated with plasma total antioxidant capacity [13] and has also related with higher diet quality, based on common indexes such as the Mediterranean diet and the Healthy Eating Scores [14]. Recently cross-sectional studies reported that dietary TAC was inversely related to plasma high-sensitive $C$ reactive protein (hs-CRP) as a marker of systemic inflammation and mediator of metabolic disorders [15], central adiposity, oxidized LDL-C concentration [13], and diabetes biomarkers [16]. Food selection based on dietary TAC in a crossover intervention also modified antioxidant intakes, systemic inflammation and liver function [17]. Although some beneficial aspects of a high TAC diet on health promotion and disease prevention have been investigated, more longitudinal and cohort studies are required to confirm these results and be prioritized in public health strategies and dietary recommendations. In the present study we investigated whether dietary TAC could affect the occurrence of MetS and related metabolic disorders after 3-year follow-up in Tehranian adults.

\section{Experimental methods}

\section{Study population}

This study was conducted within the framework of the Tehran Lipid and Glucose Study (TLGS). Briefly, TLGS is a community-based prospective study conducted to investigate and prevent non-communicable diseases, in a representative sample of residents, aged $\geq 3 y$, from district 13 of Tehran, the capital city of Iran. The first phase of the TLGS began in March 1999 and data collection, at three-year intervals, is ongoing [18].

A total of 12523 participants were examined at the third phase of the TLGS (2006-2008). Of these, 4920 participants were randomly selected for dietary assessment, categorized by age and sex categorization; data obtained using the food frequency questionnaire (FFQ) was available for 3462 participants at this phase [19]. For the current study, 2799 men and women aged 19-70 y, were recruited. Subjects were excluded if they under- or over-reported dietary intakes (less than $800 \mathrm{kcal} / \mathrm{d}$ or more than $4200 \mathrm{kcal} / \mathrm{d}$, respectively), or they were on specific diets. The final sample at baseline (2006-2008), included 2567 adults (1129 men and 1438 women) and the mean duration of the follow-up was approximately 3 years. Of the 2567 initial participants who attended the baseline examination, 629 subjects who had no follow-up information on anthropometrics and biochemical measurements were excluded and final analysis of data was performed for 1938 (75.5\%) participants.

Informed written consents were obtained from all participants and the study protocol was approved by the research council of the Research Institute for Endocrine Sciences, Shahid Beheshti University of Medical Sciences.

\section{Dietary assessment and dietary TAC calculation}

Dietary data were collected using a validated semiquantitative food frequency questionnaire (FFQ) with 168 food items. Trained dietitians, with at least 5 years of experience in the TLGS survey, asked participants to designate their intake frequency for each food item consumed during the past year on a daily, weekly, or monthly basis. Portion sizes of consumed foods reported in household measures were then converted to grams [19].

Because the Iranian Food Composition Table (FCT) is incomplete, and has limited data on nutrient content of raw foods and beverages, to analyze foods and beverages for their energy and nutrient content we used the US Department of Agriculture (USDA) FCT [17].

Dietary TAC was estimated based on the oxygen radical absorbance capacity of selected foods reported by Nutrient Data Laboratory of USDA, and expressed as $\mu$ mol of Trolox Equivalents per 100 grams of foods $(\mu \mathrm{molTE} / 100 \mathrm{~g})[20]$.

\section{Lifestyle, anthropometrics and clinical measurement}

Trained interviewers collected information using a pretested questionnaire. Information on age (years), current smoking (yes/no), educational level (illiterate, primary, academic and advanced academic education) and physical activity (MET-h/wk) were assessed at baseline examination (2006-2008). Smoking status was obtained using face-to-face interviews and subjects who smoked daily or occasionally were considered current smokers, while non-smoker included those who had never smoked or those who had quit smoking. Physical activity level was assessed using the Krishna et al. questionnaire [21] to obtain frequency and time spent on light, moderate, hard and very hard intensity activities according to the list of common activities of daily life over the past year. Physical activity levels were expressed as metabolic equivalent hours per week (METs $h / w k$ ).

Anthropometric measurements were assessed at baseline and again after a 3-year follow-up by trained staff. Weight was measured to the nearest $100 \mathrm{~g}$ using digital scales, while the subjects were minimally clothed, without shoes. Height was measured to the nearest $0.5 \mathrm{~cm}$, in a standing position without shoes, using a tape meter. Waist circumference (WC) were measured to the 
nearest $0.1 \mathrm{~cm}$ (at anatomical landmarks), at the widest portion, over light clothing, using a soft, tape meter, without any pressure to the body. Body mass index was calculated as weight $(\mathrm{kg})$ divided by square of the height $\left(\mathrm{m}^{2}\right)$.

For blood pressure (BP) measurements, after a 15minute rest in the sitting position, two measurements of BP were taken, on the right arm, using a standardized mercury sphygmomanometer; the mean of the two measurements was considered as the participant's BP.

\section{Biochemical measurement}

Fasting blood samples were taken after 12-14 h, from all study participants at baseline and after a 3-year followup. Fasting plasma glucose (FPG) was measured by the enzymatic colorimetric method using glucose oxidase. Triglyceride (TG) level was measured by enzymatic colorimetric analysis with glycerol phosphate oxidase. High-density lipoprotein cholesterol (HDL-c) was measured after precipitation of the apolipoprotein B containing lipoproteins with phosphotungstic acid. Analyses were performed using Pars Azmoon kits (Pars Azmoon Inc., Tehran, Iran) and a Selectra 2 auto-analyzer (Vital Scientific, Spankeren, Netherlands). Inter- and intraassay coefficient of variation of all assays was $<5 \%$.

\section{Definition of metabolic syndrome and its components}

Cardio-metabolic risk factors for the metabolic syndrome were defined according to the diagnostic criteria proposed by NCEP ATP III [22], and new cutoff points of waist circumference for Iranian adults [23]; the syndrome was characterized as having at least 3 of the metabolic abnormalities: 1) Hyperglycemia as FPG $\geq$ $100 \mathrm{mg} / \mathrm{dL}(5.6 \mathrm{mmol} / \mathrm{L})$ or drug treatment of impaired fasting glucose, 2) Hypertriglyceridemia as serum $\mathrm{TG} \geq 150 \mathrm{mg} / \mathrm{dL}(1.69 \mathrm{mmol} / \mathrm{L})$ or drug treatment, 3) Low HDL-c as serum HDL-cholesterol $<40 \mathrm{mg} / \mathrm{dL}$ $(1.04 \mathrm{mmol} / \mathrm{L})$ for men, and $<50 \mathrm{mg} / \mathrm{dL}(1.29 \mathrm{mmol} / \mathrm{L})$ for women or drug treatment, 4) Hypertension as $\mathrm{BP} \geq$ $130 / 85 \mathrm{mmHg}$ or drug treatment for hypertension, and 5) Abdominal obesity as $\mathrm{WC} \geq 95 \mathrm{~cm}$ for both genders.

\section{Statistical methods}

All statistical analysis were conducted using SPSS (Version 16.0; Chicago, IL), and $P$ values $<0.05$ were considered significant. Participant characteristics, the mean of MetS components and the prevalence of MetS and its features were compared at baseline across quartile categories of dietary TAC, using the general linear models with adjusted for sex and age or the Chi-square test. Mean dietary intakes of participants were compared across quartile categories of dietary TAC using the general linear model with adjustment for sex, age (y, continuous), and energy intakes $(\mathrm{kcal} / \mathrm{d})$. The association of dietary TAC and MetS components at the first examination, in each quartile category, was measured by using the linear regression model with adjustment for sex, age (y, continuous), BMI ( $\mathrm{kg} / \mathrm{m}^{2}$, continuous), education (4 categories), smoking (yes or no), physical activity (MET$\mathrm{h} / \mathrm{wk}$, continuous), total energy intake ( $\mathrm{kcal} / \mathrm{d})$, percent of energy from dietary carbohydrate, protein, total fat, saturated fat, mono and poly-unsaturated fat, and total fiber $(\mathrm{g} / 1000 \mathrm{kcal} / \mathrm{d})$.

Changes of metabolic syndrome components, during the 3-year follow-up, were calculated as [(follow-up measure - baseline measure) / baseline measure] $\times 100$, and were compared across TAC quartiles using the general linear models, adjusted for baseline confounding variables.

To estimate the odds ratio of MetS and components in each quartile category of dietary TAC at the second examination, participants with metabolic disorders at baseline were excluded from the analysis; based on this, the multivariable logistic regression models, adjusted for the above-mentioned potential confounders, analyses were conducted on 1447 subjects for the MetS, 1276 subjects for abdominal obesity, 1672 subjects for impaired fasting glucose, 1252 subjects for hypertriglyceridemia, 592 subjects for low-HDL-c, and 1577 subjects for hypertension. Dietary potassium intake $(\mathrm{mg} /$ $1000 \mathrm{kcal} / \mathrm{d}$ ) was additionally adjusted for the assessment of dietary TAC in relation to 3 -year changes of systolic and diastolic blood pressure and the occurrence of hypertention.

To assess the overall trends of odds ratios of metabolic syndrome and its components across quartiles of dietary TAC, the median of each quartile was used as a continuous variable in the logistic regression models.

\section{Results}

The mean age of participants was $40.4 \pm 13.0 \mathrm{y}$, and mean BMI was $27.03 \pm 4.9 \mathrm{~kg} / \mathrm{m}^{2}$ at baseline. Fortyseven percent of participants were men. The mean weight gain was $1.49 \pm 5.06 \mathrm{~kg}(1.65 \pm 5.3 \mathrm{~kg}$ in men and $1.34 \pm 4.9 \mathrm{~kg}$ in women) during the 3-year period; lower weight gain during 3 -year follow-up was observed in the participants with the higher TAC diet $(0.9 \mathrm{~kg}$ in fourth quartile vs. $1.9 \mathrm{~kg}$ in first quartile, $P<0.05)$. The mean of dietary TAC was $962 \pm 189 \mu$ molTE per $100 \mathrm{~g}$ of food intakes $(929 \pm 186$ in men and $986 \pm 187$ in women $\mu$ molTE/100 g). Participants in the highest TAC quartile category were more likely to be women than men (57 vs. $43 \%, P$ for trend $<0.05$ ), were older (37 vs. 43 years, $P$ for trend $<0.001)$, and were less likely to be current smokers $(9.2$ vs. $13.7 \%, P$ for trend $<0.01)$. Participants in the highest TAC quartile also spent more time for leisure physical activity $(P<0.05)$. There was no 
significant difference between the educational status of participants across quartile categories (Table 1).

The mean \pm SEM of the MetS components and the prevalence of MetS and its risk factors across categories of dietary TAC at baseline are presented in Table 2 . There were no significant differences between the MetS and its components in the participants at baseline. The mean dietary intake of participants across dietary TAC quartile categories are shown in Table 3. There was no difference in total energy intakes and calorie intakes from macronutrients between the dietary TAC quartile categories but there was a significant decreasing trend in dietary energy density from lower to upper TAC scores. Dietary intakes of vitamin A, total carotenoids, vitamin $\mathrm{E}, \mathrm{C}$, and zinc were significantly higher in participants with higher TAC diet. Moreover, participants in the highest quartile of dietary TAC had consumed more whole grains, fruits, legumes, dairy and nuts.

Baseline associations of dietary TAC and the MetS components in each quartile category, as $\beta$ regression and $95 \% \mathrm{CI}$, are presented in Table 4 . Dietary TAC were negatively associated with WC, FPG, TG and BP, and positively associated with HDL-c levels; these associations strengthened across increasing dietary TAC.

The mean percent of 3-year changes in MetS components are provided in Figure 1. Participants with the highest TAC score had lower abdominal fat gain during the study follow-up. The odds ratio and 95\% CI for the MetS and its components across dietary TAC quartiles are shown in Figure 2. After adjustment for potential confounding variables, the chance of having the MetS, abdominal obesity and hypertension after a 3 year follow-up decreased across the increasing dietary TAC quartile $(P$ for trend $<0.01)$. Dietary TAC over 1080 $\mu \mathrm{molTE} / 100 \mathrm{~g}$ of food, resulted in $38 \%$ decrease the risk of abdominal obesity $(\mathrm{OR}=0.62,95 \% \mathrm{CI}=0.38-0.99)$.

\section{Discussion}

The most important findings of this study were an inverse association between dietary TAC and the MetS components at the baseline examination, and the lower occurrence of abdominal obesity after a 3-year follow-up in individuals who had higher dietary TAC. Higher intake of dietary antioxidants also resulted in lower weight and abdominal fat gain during the study period. However although there was no significant decrease in the occurrence of MetS and other metabolic disorders, a significant decreasing trend in the chance of having the MetS and hypertension along with the increase of dietary TAC was observed.

The association of dietary TAC and the MetS components at baseline observed in our study are in agreement with other similar studies that indicated dietary total antioxidant intakes were negatively correlated with lower fasting blood glucose, insulin concentrations, and homeostasis model assessment of insulin resistance in healthy subjects as well as pre diabetic and diabetic patients [16]. Dietary TAC also had inverse association with abdominal obesity, glycemia, total cholesterol to HDL-c ratio, TG, oxidized LDL-C concentration [13]

Table 1 Characteristics of participants by categories of dietary total antioxidant capacity at baseline: Tehran Lipid and Glucose Study ${ }^{1}$

\begin{tabular}{|c|c|c|c|c|c|}
\hline & \multicolumn{5}{|c|}{$(n=1938)$} \\
\hline & Q1 & Q2 & Q3 & Q4 & $P^{2}$ \\
\hline \multicolumn{6}{|l|}{ Total antioxidant capacity } \\
\hline Range & $<842$ & $842-958$ & $959-1080$ & $>1080$ & \\
\hline Median & 764 & 906 & 1014 & 1161 & \\
\hline Age at baseline (yr) & $37.0 \pm 0.6$ & $40.2 \pm 0.5$ & $41.4 \pm 0.5$ & $43.0 \pm 0.5$ & $<0.001$ \\
\hline Men (\%) & 53.9 & 46.8 & 39.0 & 34.5 & $<0.001$ \\
\hline \multicolumn{6}{|l|}{ Physical activity (Met-h/week) } \\
\hline Job activity & $29.2 \pm 2.3$ & $26.7 \pm 2.3$ & $22.5 \pm 2.3$ & $26.0 \pm 2.3$ & 0.25 \\
\hline Leisure time activity & $8.2 \pm 0.7$ & $9.9 \pm 0.7$ & $10.2 \pm 0.7$ & $12.0 \pm 0.7$ & 0.005 \\
\hline Total & $37.5 \pm 2.5$ & $36.6 \pm 2.4$ & $32.7 \pm 2.4$ & $38.1 \pm 2.4$ & 0.41 \\
\hline Current smoker (\%) & 13.7 & 11.0 & 10.8 & 9.2 & 0.16 \\
\hline \multicolumn{6}{|l|}{ Education status (\%) } \\
\hline Illiterate & 2.5 & 1.7 & 2.3 & 2.7 & 0.73 \\
\hline Primary education & 7.5 & 3.2 & 6.5 & 0 & 0.81 \\
\hline Academic education & 81.1 & 90.3 & 83.9 & 91.3 & 0.81 \\
\hline Advanced academic education & 11.3 & 6.5 & 9.7 & 8.7 & 0.81 \\
\hline
\end{tabular}

${ }^{1}$ Data are age- and sex-adjusted mean \pm SEM.

${ }^{2} P$ for trend across quartiles of dietary phytochemical index was calculated using Chi square test or linear regression models with adjustment for sex and age. 
Table 2 Metabolic syndrome components and prevalence of metabolic syndrome and its risk factors by categories of dietary total antioxidant capacity: Tehran Lipid and Glucose Study ${ }^{1}$

\begin{tabular}{|c|c|c|c|c|c|}
\hline & \multicolumn{5}{|c|}{$(n=1938)$} \\
\hline & Q1 & Q2 & Q3 & Q4 & $P^{2}$ \\
\hline \multicolumn{6}{|l|}{ Total antioxidant capacity } \\
\hline Range & $<842$ & $842-958$ & $959-1080$ & $>1080$ & \\
\hline Median & 764 & 906 & 1014 & 1161 & \\
\hline Waist circumference $(\mathrm{cm})$ & $90 \pm 0.5$ & $89.0 \pm 0.5$ & $89 \pm 0.5$ & $89 \pm 0.5$ & 0.44 \\
\hline Fasting blood glucose (mg/dl) & $93 \pm 1.1$ & $91 \pm 1.1$ & $91 \pm 1.1$ & $90 \pm 1.1$ & 0.46 \\
\hline Serum triglycerides (mg/dl) & $148 \pm 3.7$ & $142 \pm 3.7$ & $143 \pm 3.7$ & $137 \pm 3.7$ & 0.24 \\
\hline $\mathrm{HDL}-\mathrm{c}(\mathrm{mg} / \mathrm{dl})$ & $42.2 \pm 0.4$ & $41.8 \pm 0.4$ & $42.2 \pm 0.4$ & $42.5 \pm 0.4$ & 0.71 \\
\hline $\mathrm{SBP}(\mathrm{mmHg})$ & $112 \pm 0.6$ & $112 \pm 0.6$ & $111 \pm 0.6$ & $111 \pm 0.6$ & 0.75 \\
\hline $\mathrm{DBP}(\mathrm{mmHg})$ & $74 \pm 0.4$ & $74 \pm 0.4$ & $73 \pm 0.4$ & $73 \pm 0.4$ & 0.12 \\
\hline Abdominal obesity (\%) & 44.2 & 43.7 & 46.5 & 38.8 & 0.10 \\
\hline Hypertriglyceridemia (\%) & 34.5 & 31.8 & 30.7 & 31.1 & 0.57 \\
\hline Low HDL-c (\%) & 49.2 & 50.9 & 51.2 & 47.6 & 0.65 \\
\hline Hyperglycemia (\%) & 22.7 & 25.2 & 24.1 & 28.0 & 0.28 \\
\hline Hypertension (\%) & 12.6 & 17.4 & 14.5 & 15.5 & 0.20 \\
\hline Metabolic syndrome (\%) & 24.6 & 27.5 & 27.4 & 25.9 & 0.69 \\
\hline
\end{tabular}

${ }^{1}$ Data are age-adjusted mean \pm SEM.

${ }^{2} P$ for trend across quartiles of dietary phytochemical index was calculated using Chi square test or linear regression models with adjustment for sex and age.

and hs-CRP concentration [15]. Higher intakes of total antioxidant in another cross-sectional study were negatively related with body mass index, systolic blood pressure, serum glucose and free fatty acids [24]. Plasma TAC as a relevant representative indicator of dietary TAC also had a consistent and independent relationship with all obesity indices in men and women [25].

Similar to data available in the current study higher dietary TAC was introduced better diet quality and was related to higher consumption of fruits and vegetables, whole grains, legumes and nuts. The favorable effects of these antioxidant rich foods on improvement of lipid profiles, glucose homeostasis, ameliorating insulin resistance, adiposity and obesity have been investigated in pre-clinical and some clinical studies. Current data suggest that potential effects of food antioxidants such as polyphenols, carotenoids and vitamins may occur through modification of lipids and carbohydrate metabolism, increased insulin sensitivity, and regulation of both appetite and adipocytokines [26]. The anti-obesity effects of high TAC diet during 3-years, investigated in our study may be helpful in validating the oxidative stress-induced obesity hypothesis [27]. Based on this hypothesis, a potential therapeutic role has been considered for dietary antioxidant supplementation in reduction of body weight or improvement of several obesity related disorders [28,29]. In addition, dietary antioxidants also affect other aspects of obesity-related metabolic pathways including inhibition of intestinal fat abortion, promotion of catabolism in adipose tissue, inhibition of proliferation, differentiation, angiogenesis in pre adipocytes, and induction of apoptosis in mature adipocytes [30,31]. Some other dietary antioxidant could prevent adiposity by regulation of brown adipose tissue metabolism and increase thermogenesis, decrease adiponectin and leptin gene expression in adipocytes $[32,33]$.

Since, to our knowledge, the longitudinal association between dietary TAC and MetS components has not yet been evaluated, it is not possible to compare and discuss our longitudinal findings with those of others; hence inevitably we discuss here the effects of serum antioxidant and antioxidant supplementation on the risk of MetS and its components. In a 7.5 yr follow-up study, baseline serum antioxidant concentration including, serum $\beta$-carotene and vitamin $C$ was negatively, while plasma zinc was positively associated with incidence risk of the MetS; serum concentrations of vitamin E had no influence on occurrence of the MetS [7]. Clinical trials with antioxidants supplementation showed inconsistent results regarding their ability to reduce the risk of MetS and other related metabolic disorders. No beneficial effects on fasting blood glucose, and the risk of hypertension and MetS, and adverse effects on lipid profiles were observed in longitudinal supplementations with nutritional doses of antioxidant vitamins and minerals $[7,8]$. Considering the possible different effects of dietary sources or supplement 
Table 3 Dietary intakes of participants by categories of dietary total antioxidant capacity: Tehran Lipid and Glucose Study ${ }^{1}$

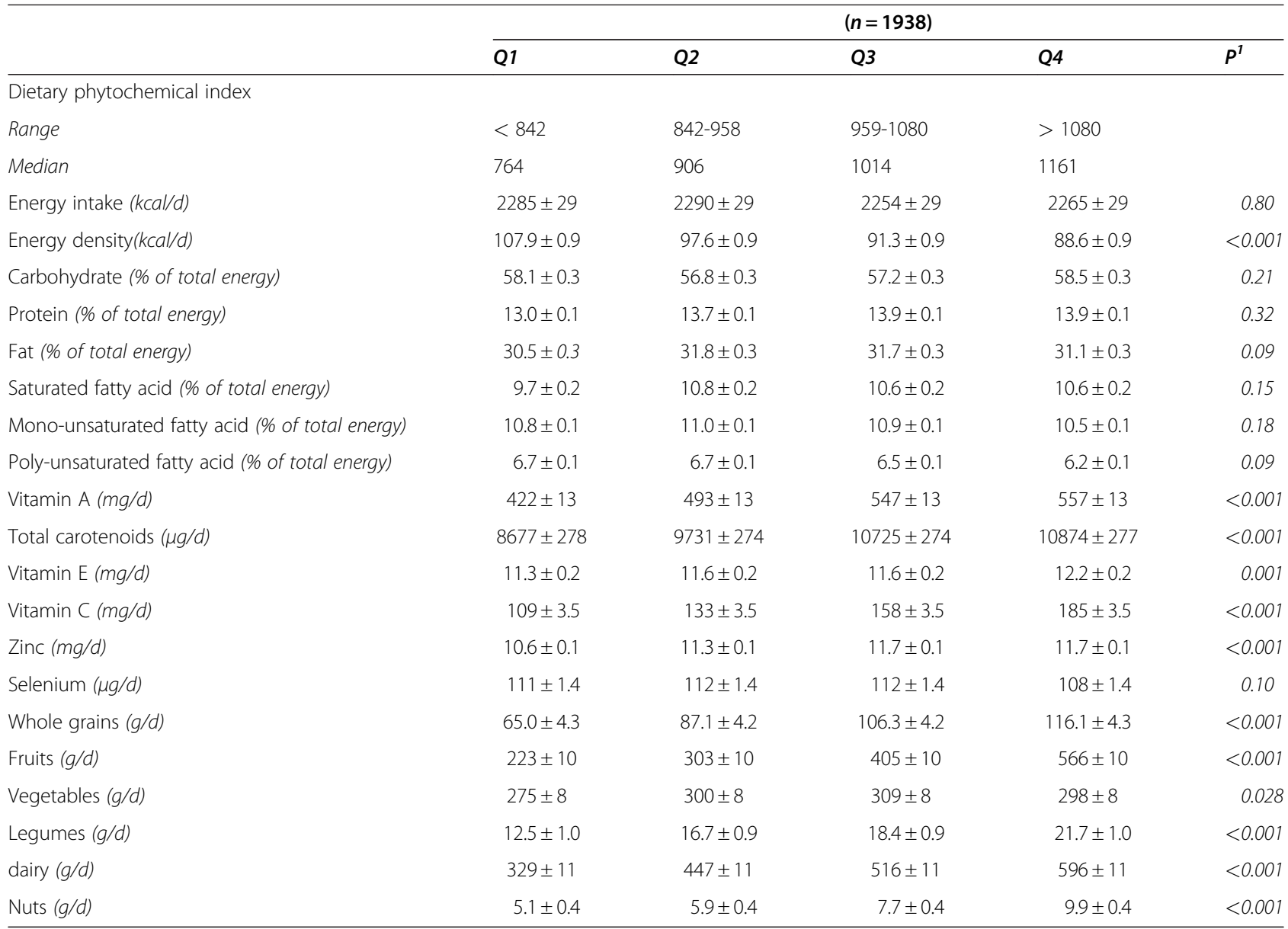

${ }^{1}$ Data are age-and energy adjusted mean \pm SEM.

${ }^{2} P$ values compared the dietary intakes of participants across quartiles of dietary phytochemical index using linear regression models with adjustment of sex, age and energy intakes.

Table 4 The association of dietary TAC and metabolic syndrome components at baseline (2006-2008): Tehran Lipid and Glucose Study ${ }^{1}$

\begin{tabular}{|c|c|c|c|c|c|}
\hline & \multicolumn{5}{|c|}{$(n=1938)$} \\
\hline & Q1 & Q2 & Q3 & Q4 & $P$ for trend \\
\hline \multicolumn{6}{|l|}{ Total antioxidant capacity } \\
\hline Range & $<16788$ & $16788-22518$ & 22518-29249 & $>29249$ & \\
\hline Mean & 15333 & 20842 & 24648 & 29857 & \\
\hline Waist circumference & 0 & $-1.6(-2.56,-0.72)$ & $-2.22(-3.14,-1.29)$ & $-3.89(-4.82,-2.95)$ & $<0.01$ \\
\hline Fasting blood glucose & 0 & $-2.41(-5.22,0.40)$ & $-2.38(-5.19,0.44)$ & $-3.02(-5.87,-0.17)$ & $<0.01$ \\
\hline Serum triglycerides & 0 & $-9.27(-19.70,1.17)$ & $-10.54(-21.0,-0.08)$ & $-19.22(-29.8,-8.64)$ & 0.24 \\
\hline HDL-cholesterol & 0 & $0.28(-0.96,1.53)$ & $1.31(0.06,2.57)$ & $2.24(0.97,3.5)$ & $<0.01$ \\
\hline Systolic blood pressure & 0 & $-0.17(-1.74,1.48)$ & $-1.52(-3.21,0.39)$ & $-2.53(-4.41,-0.65)$ & $<0.01$ \\
\hline Diastolic blood pressure & 0 & $-0.01(-1.15,1.34)$ & $-1.23(-2.45,-0.19)$ & $-2.19(-3.33,-0.97)$ & $<0.01$ \\
\hline
\end{tabular}

${ }^{1}$ Data are $\beta$ regression and $95 \% \mathrm{Cl}$ (Linear regression models were used with adjustment for age, sex, body mass index, physical activity, smoking status, energy and macronutrient intakes; Dietary potassium intake $(\mathrm{mg} / 1000 \mathrm{kcal} / \mathrm{d})$ was additionally adjusted for systolic and diastolic blood pressure). 


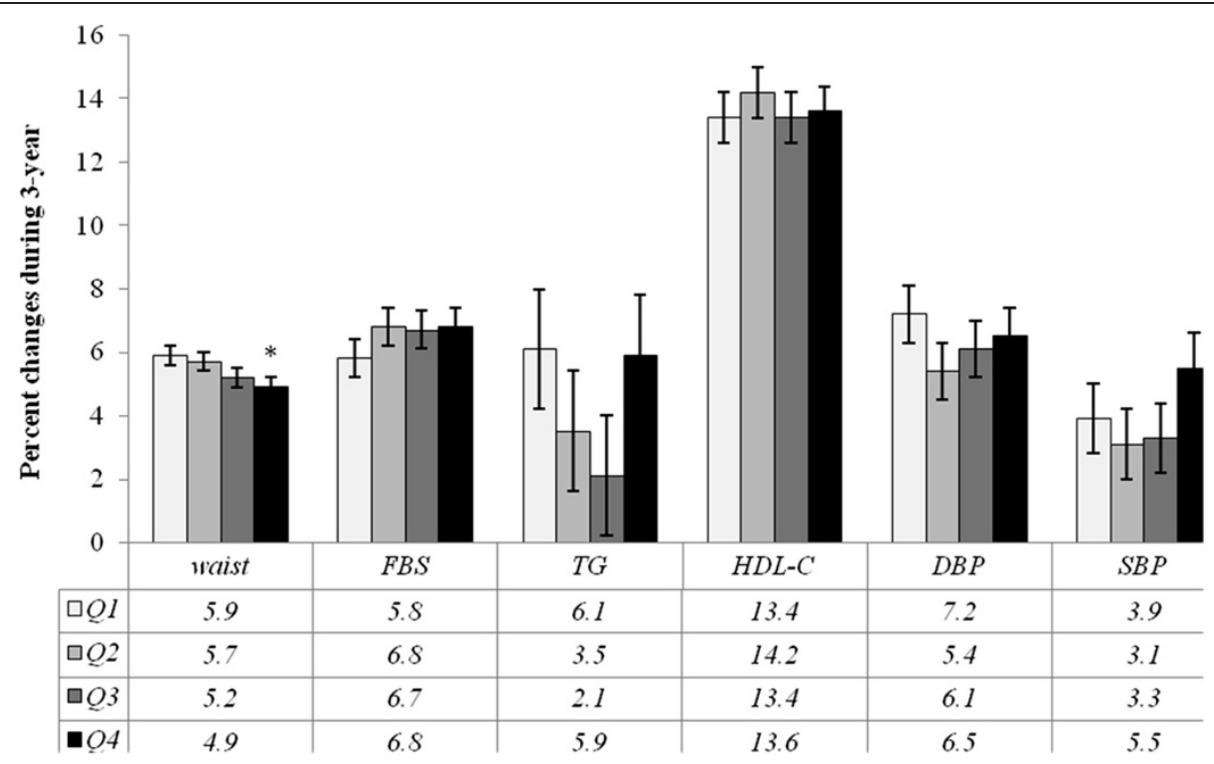

Figure 1 Percent change of the MetS components across quartile categories of dietary TAC during 3-year follow-up. General linear models with adjustment for potential confounding variables were used to compare the percent changes of the MetS components between the quartile categories of the dietary TAC ( $\left.{ }^{*} \mathrm{P}<0.05\right)$. FBS: Fasting blood glucose, TG: Triglycerides, HDL-c: High density lipoprotein cholesterol, SBP: Systolic blood pressure, DBP: Diastolic blood pressure.

sources of antioxidants, longitudinal studies are needed to investigate the impacts of high TAC diets on several aspects of human health.

Some limitations of the current study should be considered; usual dietary intakes of participants were only assessed at baseline, while several evaluations of dietary intakes could have increased the validity of the results.
Using the USDA FCT rather than a complete Iranian FCT is another limitation.

\section{Conclusion}

In conclusion, we demonstrated that higher dietary antioxidant intakes have favorable effects on metabolic disorders and more interestingly prevent subsequent
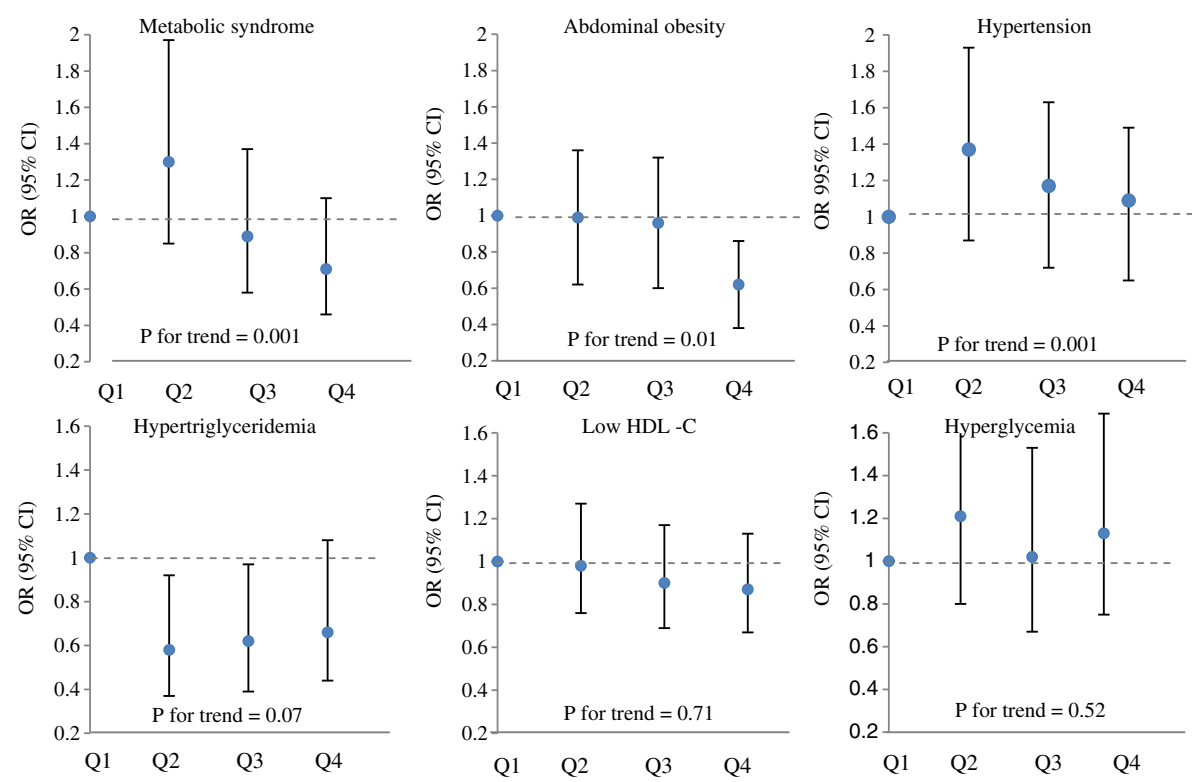

Figure 2 Odds and $95 \%$ confidence interval for occurrence of the MetS and its components in each quartile categories of dietary TAC after 3-year follow-up. Logistic regression models with adjustment for potential confounding variables were used to OR estimation. 
weight and abdominal fat gain during a 3-year followup. This study provides further evidence to recommend antioxidant-rich foods as a useful tool in health promotion and disease prevention. In addition to current guidelines recommending increase in consumption of whole-plant foods, focusing on food selection based on antioxidant content of foods certainly would definitely be more effective.

\section{Competing interest}

The authors declare that they have no conflict of interest.

\section{Authors' contribution}

The project was designed and implemented by Z.B and P.M. Data were analyzed and interpreted Z.B and M.G. Z.B, M.G, N.SH and F.A prepared the manuscript. P.M, and F.A supervised overall project. "All authors read and approved the final version of manuscript".

\section{Acknowledgment}

We thank the TLGS participants and the field investigators of the TLGS for their assistance in physical examinations, biochemical and nutritional evaluation and database management. This study was supported by grant 121 from National Research Council of the Islamic Republic of Iran and the Research Institute for Endocrine Sciences of Shahid Beheshti University of Medical Sciences.

\section{Author details}

${ }^{1}$ Nutrition and Endocrine Research Center, Research Institute for Endocrine Sciences, Shahid Beheshti University of Medical Sciences, No 24 Parvaneh St., Yemen St., Chamran Exp., Tehran 19395-4763, Iran. ${ }^{2}$ Department of Clinical Nutrition and Dietetics, Faculty of Nutrition Sciences and Food Technology, National Nutrition and Food Technology Research Institute, Shahid Beheshti University of Medical Sciences, No 46 Arghavan-e-gharbi St., Farahzadi Blv., Shahrak-e-Ghods, 19395-4741 Tehran, Iran. ${ }^{3}$ Endocrine Research Center, Research Institute for Endocrine Sciences, Shahid Beheshti University of Medical Sciences, No 24 Parvaneh St., Yemen St., Chamran Exp., Tehran 19395-4763, Iran

Received: 27 May 2012 Accepted: 13 July 2012

Published: 31 July 2012

\section{References}

1. Alberti KG, Zimmet P, Shaw J: IDF Epidemiology Task Force Consensus Group. The metabolic syndrome--a new worldwide definition. Lancet 2005, 366:1059-1062.

2. Zarich SW: Metabolic syndrome, diabetes and cardiovascular events: current controversies and recommendations. Minerva Cardioangiol 2006, 54:195-214.

3. Roberts CK, Sindhu KK: Oxidative stress and metabolic syndrome. Life SCi 2009, 84:705-712.

4. Ceriello A, Motz E: Is oxidative stress the pathogenic mechanism underlying insulin resistance, diabetes, and cardiovascular disease? The common soil hypothesis revisited. Arterioscler Thromb Vasc Biol 2004, 24:816-823.

5. Grattagliano I, Palmieri VO, Portincasa P, Moschetta A, Palasciano G: Oxidative stress-induced risk factors associated with the metabolic syndrome: a unifying hypothesis. J Nutr Biochem 2008, 19:491-504.

6. Frei B: Efficacy of dietary antioxidants to prevent oxidative damage and inhibit chronic disease. J Nutr 2004, 134(Suppl 11):3196-3198.

7. Czernichow S, Vergnaud AC, Galan P, Arnaud J, Favier A, Faure H, Huxley R, Hercberg S, Ahluwalia N: Effects of long-term antioxidant supplementation and association of serum antioxidant concentrations with risk of metabolic syndrome in adults. Am J Clin Nutr 2009, 90:329-335.

8. Czernichow S, Couthouis A, Bertrais S, Vergnaud AC, Dauchet L, Galan P, Hercberg S: Antioxidant supplementation does not affect fasting plasma glucose in the Supplementation with Antioxidant Vitamins and Minerals (SU.VI.MAX) study in France: association with dietary intake and plasma concentrations. Am J Clin Nutr 2006, 84:395-399.
9. Hercberg S, Preziosi P, Briançon S, Galan P, Triol I, Malvy D, Roussel AM, Favier A: A primary prevention trial using nutritional doses of antioxidant vitamins and minerals in cardiovascular diseases and cancers in a general population: the SU.VI.MAX study--design, methods, and participant characteristics. SUpplementation en Vltamines et Minéraux AntioXydants. Control Clin Trials 1998, 19:336-351.

10. Wu X, Gu L, Holden J, Haytowitz DB, Gebhardt SE, Beecher G, Prior RL: Development of a database for total antioxidant capacity in foods: a preliminary study. J Food Comps Anal 2004, 17:407-422.

11. Puchau B, Zulet MA, de Echávarri AG, Hermsdorff HH, Martínez JA: Dietary total antioxidant capacity: a novel indicator of diet quality in healthy young adults. J Am Coll Nutr 2009, 28:648-656.

12. Pellegrini N, Serafini M, Colombi B, Del Rio D, Salvatore S, Bianchi M, Brighenti F: Total antioxidant capacity of plant foods, beverages and oils consumed in Italy assessed by three different in vitro assays. J Nutr 2003, 133:2812-2819.

13. Hermsdorff HH, Puchau B, Volp AC, Barbosa KB, Bressan J, Zulet MÁ Martínez JA: Dietary total antioxidant capacity is inversely related to central adiposity as well as to metabolic and oxidative stress markers in healthy young adults. Nutr Metab (Lond) 2011, 8:59.

14. Puchau B, Zulet MA, de Echávarri AG, Hermsdorff HH, Martínez JA: Dietary total antioxidant capacity: a novel indicator of diet quality in healthy young adults. J Am Coll Nutr 2009, 28:648-656.

15. Brighenti $F$, Valtueña $S$, Pellegrini N, Ardigò $D$, Del Rio D, Salvatore S, Piatti $P$, Serafini M, Zavaroni I: Total antioxidant capacity of the diet is inversely and independently related to plasma concentration of high-sensitivity Creactive protein in adult Italian subjects. Br J Nutr 2005, 93:619-625.

16. Psaltopoulou T, Panagiotakos DB, Pitsavos C, Chrysochoou C, Detopoulou P, Skoumas J, Stefanadis C: Dietary antioxidant capacity is inversely associated with diabetes biomarkers: the ATTICA study. Nutr Metab Cardiovasc Dis 2011, 21:561-567.

17. Valtueña S, Pellegrini N, Franzini L, Bianchi MA, Ardigò D, Del Rio D, Piatti $P$, Scazzina F, Zavaroni I, Brighenti F: Food selection based on total antioxidant capacity can modify antioxidant intake, systemic inflammation, and liver function without altering markers of oxidative stress. Am J Clin Nutr 2008, 87:1290-1297.

18. Azizi F, Rahmani M, Emami H, Mirmiran P, Hajipour R, Madjid M, Ghanbili J, Ghanbarian A, Mehrabi Y, Saadat N, Salehi P, Mortazavi N, Heydarian P, Sarbazi N, Allahverdian S, Saadati N, Ainy E, Moeini S: Cardiovascular risk factors in an Iranian urban population: Tehran Lipid and Glucose Study. Soz Praventivmed 2002, 47:408-426.

19. Hosseini-Esfahani F, Jessri M, Mirmiran P, Bastan S, Azizi F: Adherence to dietary recommendations and risk of metabolic syndrome: Tehran Lipid and Glucose Study. Metabolism 2010, 59:1833-1842.

20. Haytowitz DB, Bhagwat S: USDA Database for the Oxygen Radical Absorbance Capacity (ORAC) of Selected Foods, Release 2. U.S. Department of Agriculture 2010, Available at www.ars.usda.gov/Services/ docs.htm; date of use: December 2011.

21. Kriska AM, Knowler WC, LaPorte RE, Drash AL, Wing RR, Blair SN, Bennett PH, Kuller LH: Development of questionnaire to examine relationship of physical activity and diabetes in Prima Indians. Diabetes Care 1999, 13:401-11.

22. Grundy SM, Cleeman JI, Daniels SR, Donato KA, Eckel RH, Franklin BA, Gordon DJ, Krauss RM, Savage PJ, Smith SC Jr, Spertus JA, Costa F, American Heart Association; National Heart, Lung, and Blood Institute: Diagnosis and management of the metabolic syndrome: an American Heart Association/National Heart, Lung, and Blood Institute scientific statement. Circulation 2005, 112:2735-52.

23. Azizi F, Hadaegh F, Khalili D, Esteghamati A, Hosseinpanah F, Delavari A, Larijani B, Mirmiran P, Zabetian A, Mehrabi Y, Kelishadi R, Aghajani H: Appropriate Definition of Metabolic Syndrome among Iranian Adults: Report of the Iranian National Committee of Obesity. Arch Iran Med 2010, 13:426-8.

24. Puchau B, Zulet MA, de Echávarri AG, Hermsdorff HH, Martínez JA: Dietary total antioxidant capacity is negatively associated with some metabolic syndrome features in healthy young adults. Nutrition 2010, 26:534-41.

25. Chrysohoou C, Panagiotakos DB, Pitsavos C, Skoumas I, Papademetriou L, Economou M, Stefanadis C: The implication of obesity on total antioxidant capacity in apparently healthy men and women: the ATTICA study. Nutr Metab Cardiovasc Dis 2007, 17:590-7.

26. Meydani M, Hasan ST: Dietary polyphenols and obesity. Nutrients 2010, 2:737-51. 
27. Sen S, Simmons RA: Maternal antioxidant supplementation prevents adiposity in the offspring of Western diet-fed rats. Diabetes 2010, 59:3058-65.

28. Shen XH, Tang QY, Huang J, Cai W: Vitamin E regulates adipocytokine expression in a rat model of dietary-induced obesity. Exp Biol Med (Maywood) 2010, 235:47-51.

29. Shen $X$, Tang $Q$, Wu J, Feng Y, Huang J, Cai W: Effect of vitamin E supplementation on oxidative stress in a rat model of diet-induced obesity. Int J Vitam Nutr Res 2009, 79:255-63.

30. Fukuchi Y, Hiramitsu M, Okada M, Hayashi S, Nabeno Y, Osawa T, Naito M: Lemon Polyphenols Suppress Diet-induced Obesity by Up-Regulation of mRNA Levels of the Enzymes Involved in beta-Oxidation in Mouse White Adipose Tissue. J Clin Biochem Nutr 2008, 43:201-9.

31. Lee MS, Kim CT, Kim Y: Green tea (-)-epigallocatechin-3-gallate reduces body weight with regulation of multiple genes expression in adipose tissue of diet-induced obese mice. Ann Nutr Metab 2009, 54:151-7.

32. Zulet MA, Puchau B, Hermsdorff HH, Navarro C, Martínez JA: Vitamin A intake is inversely related with adiposity in healthy young adults. $J$ Nutr Sci Vitaminol (Tokyo) 2008, 54:347-52.

33. Detopoulou P, Panagiotakos DB, Chrysohoou C, Fragopoulou E, Nomikos T, Antonopoulou S, Pitsavos C, Stefanadis C: Dietary antioxidant capacity and concentration of adiponectin in apparently healthy adults: the ATTICA study. Eur J Clin Nutr 2010, 64:161-8.

doi:10.1186/1743-7075-9-70

Cite this article as: Bahadoran et al:: Dietary total antioxidant capacity and the occurrence of metabolic syndrome and its components after a 3-year follow-up in adults: Tehran Lipid and Glucose Study. Nutrition \& Metabolism 2012 9:70.

\section{Submit your next manuscript to BioMed Central and take full advantage of:}

- Convenient online submission

- Thorough peer review

- No space constraints or color figure charges

- Immediate publication on acceptance

- Inclusion in PubMed, CAS, Scopus and Google Scholar

- Research which is freely available for redistribution 